\title{
How involved do you want to be in a non-symmetric relationship?
}

DOI:

10.1080/00048402.2013.788046

\section{Document Version}

Submitted manuscript

Link to publication record in Manchester Research Explorer

\section{Citation for published version (APA):}

Macbride, F. (2014). How involved do you want to be in a non-symmetric relationship? Australasian Journal of Philosophy, 92(1), 1-16. https://doi.org/10.1080/00048402.2013.788046

\section{Published in:}

Australasian Journal of Philosophy

\section{Citing this paper}

Please note that where the full-text provided on Manchester Research Explorer is the Author Accepted Manuscript or Proof version this may differ from the final Published version. If citing, it is advised that you check and use the publisher's definitive version.

\section{General rights}

Copyright and moral rights for the publications made accessible in the Research Explorer are retained by the authors and/or other copyright owners and it is a condition of accessing publications that users recognise and abide by the legal requirements associated with these rights.

\section{Takedown policy}

If you believe that this document breaches copyright please refer to the University of Manchester's Takedown Procedures [http://man.ac.uk/04Y6Bo] or contact uml.scholarlycommunications@manchester.ac.uk providing relevant details, so we can investigate your claim.

\section{OPEN ACCESS}




\section{HOW INVOLVED DO YOU WANT TO BE IN A NON-SYMMETRIC RELATIONSHIP?}

Fraser MacBride

Please do not cite this version. Published in Australasian Journal of Philosophy, Australasian Journal of Philosophy (2014), 92, pp. 1-16.

ABSTRACT: There are three different degrees to which we may allow a systematic theory of the world to embrace the idea of relatedness - supposing realism about non-symmetric relations as a background requirement. (First Degree) There are multiple ways in which a non-symmetric relation may apply to the things it relates - for the binary case, $a R b \neq b R a$. (Second Degree) Every such relation has a distinct converse-for every $R$ such that $a R b$ there is another relation $R^{*}$ such that $b R^{*} a$. (Third Degree) Each one of them applies in an order to the things it relates-with regard to the state that result from $R$ 's applying to a and $b$, either $R$ applies to $a$ first and $b$ second, or it applies to $b$ first and a second. Whereas the first degree is near indubitable, embracing the second or third generates unwholesome consequences. The second degree embodies a commitment to the existence of a superfluity of distinct converses and states to which such relations give rise. The third degree embodies commitment to recherché facts of the matter about how the states that arise from the application of one non-symmetric relation compare to any other. It is argued that accounts that purport to offer an analysis of the first degree generate unwelcome second or third degree consequences. This speaks in favour of our adopting an account of the application of relations that's not an analysis at all, an account that takes the first degree as primitive.

Keywords: relations, converse, analysis, Fine, Russell, Williamson

\section{Introduction}

This world in which we find ourselves is a totality of related things, a breathtaking abundance of things arranged thus-and-so rather than so-andthus-one thing being inside another, one event being before another and so on. We can posit non-symmetric relations to explain things and events being so related, but simply acknowledging their bare existence isn't enough. If nonsymmetric relations are to be any more than theoretically inert posits floating idly in the platonic void, we need an account of how these relations apply to the things and events they relate. Otherwise a philosophy of relations is no less unsatisfactory than a philosophy of mathematics that ignores its 
applications. This paper explores the prospects for constructing a viable account of the application of relations where relations are conceived as worldly items capable of relating different things and events - as universals.

It was Russell, impressed by the extent to which science and mathematics rely upon relations, who first emphasised the need for an account of their application. ${ }^{1} \mathrm{He}$ declared it to be a "fundamental logical fact" about relations that they are capable of holding between their relata in a profusion of different ways. For example, the before relation is capable of holding between events $A$ and $B$ in two different ways: witness the difference between $A$ 's being before $B$ and $B$ 's being before $A$. In The Principles of Mathematics (1903) Russell proposed to account for the capacity of relations to apply in these different ways by appealing to the "sense" or "direction" of a relation. If $A$ is before $B$ this is because the before relation proceeds from $A$ to $B$; whereas if $B$ is before $A$ this is because before proceeds in the opposite direction, i.e. from $B$ to $A$ ( $\$ 218)$.

Subsequently a number of accounts have been suggested, inter aliis by Williamson, Fine and van Inwagen, of how relations are capable of applying to the things they relate in different ways. These accounts all have something in common. They provide discursive analyses of how relations pull off the trick of arranging things thus-and-so rather than so-and-thus. They deploy a richer range of concepts at some deeper level of analysis-for example, the concept of direction - to explain how relations accomplish this feat. But another explanatory strategy is to accept the application of relations as primitive. In this paper I will advance an account of this second variety. I will argue that the capacity of a non-symmetric relation $R$ to apply to the objects $a$ and $b$ it relates so that $a R b$ rather than $b R a$ must be taken as

\footnotetext{
${ }^{1}$ For a defence of the view that contemporary physics relies upon relations see Butterfield [2006, 2011]. Butterfield argues that a physical theory's fundamental quantities cannot be construed as intrinsic properties of spacetime points but must be conceived as essentially relational in character. Butterfield extends his case not only to velocity but to other mechanical notions such as stress, strain and elasticity that are represented using vectors and tensors. For the corresponding claim that contemporary mathematics relies upon relations see [Shapiro 1991: 96-118, 221].
} 
ultimate and irreducible. Accounts that purport to provide discursive analyses of how relations apply are no better off in point of real explanatory power.

It's a familiar thought that we cannot account for the fact that one thing bears a relation $R$ to another by appealing to a further relation relating $R$ to them - that way Bradley's regress beckons. To avoid the regress we must recognise that a relation is not related to the things it relates, however language may mislead us to think otherwise. We simply have to accept as primitive, in the sense that it cannot be further explained, the fact that one thing bears a relation to another [Armstrong 1978a: 106-11, Lewis 2002: 6-7]. But it is not only the fact that one thing bears a (non-symmetric) relation $R$ to another that needs to be recognised as ultimate and irreducible. How $R$ applies - whether the $a R b$ way or the $b R a$ way-needs to be taken as primitive too.

\section{Three Degrees of Relatedness}

To clarify the costs and benefits of different accounts of relatedness it needs to be understood that the very idea of relatedness admits of different degrees so that when we come to explain how relations apply we may embrace the idea of relatedness to varying degrees. Supposing realism about nonsymmetric relations and confining our attention to determinate ones, the first or least degree of acceptance is this. For any non-symmetric relation, there are multiple ways in which it may apply to the things it relates. There are two different ways in which a binary non-symmetric relation $R$ may hold between two things, six different ways in which a ternary non-symmetric $S$ may hold between three things, and so on. ${ }^{2}$

\footnotetext{
${ }^{2}$ The idea that $a R b$ is different from $b R a$ relies upon an appreciation of the fact that there are two distinct states that potentially arise from the application of non-symmetric $R$ to $a$ and $b$. Appreciation of this fact doesn't require us to speak a language that relies upon word order to convey information about how relations configure their terms. It's, e.g. what's also appreciated by a Latin speaker when they understand that "Marius amat Mariam" describes a quite different state from "Maria amat Marium" where the difference between $a R b$ and $b R a$ is conveyed by means of declining the nouns.
} 
Relatedness to the first degree presupposes the significance of comparisons between the different ways that a relation potentially applies to its terms-presupposes because the first degree distinguishes between the way that $R$ applies to $a$ and $b$ when $a R b$ and the way it applies to them when $b R a$. But the first degree is silent about the intelligibility, or otherwise, of comparisons between, on the one hand, the ways that $R$ can apply to its terms and, on the other, the ways that relations distinct from $R$ potentially apply to their terms.

Relatedness to the second degree involves the notion of a converse. Given any non-symmetric relation $R$, the relation $R^{\star}$ that $b$ bears to $a$ whenever $a$ bears $R$ to $b$ is the converse of $R$-for $a$ to have one to $b$ is for $b$ to have the other to $a$. In general these relations are distinct. Since $R$ is nonsymmetric, there are possible circumstances in which $a$ bears $R$ to $b$ whilst $b$ doesn't bear $R$ to $a$. But because its converse $R^{*}$ is borne by $b$ to $a$ whenever $R$ is borne by $a$ to $b$ it follows that $R$ and $R^{\star}$ must be distinct. So to embrace the second degree is to make the existential assumption that every nonsymmetric relation has a distinct converse $\left(R \neq R^{*}\right)$. Before and after, above and below, greater and less provide candidate examples of pairs of mutually converse relations. The second degree outstrips the first not only because of its ontological commitment to converses but because ideologically it presupposes the significance of comparisons between the different ways that a relation $R$ and another relation, its converse $R^{*}$, potentially apply to the things they relate.

The third degree involves the notion of an absolute ordering. To embrace the third degree is to assume that for any given non-symmetric relation $R$ that holds between the objects $a$ and $b$, there is a fact of the matter about which of these objects $R$ applies to first, which second. This goes beyond the second degree because embracing it enables us to make significant inter-state comparisons between the ways in which arbitrary relations (not only converses) apply to the things they relate. Suppose that there are states $a R b$ and $c T d$ where $R$ and $T$ are arbitrary relations. Then looking across these states we can significantly ask the question whether $R$ 
really applies to $a$ first and if it does whether $T$ really applies to $c$ first too. And we can expect there to be a fact of matter about whether coming first in their respective states is something $a$ and $c$ really have in common.

Since the second degree remains silent about the significance of such comparisons between the states to which arbitrary relations give rise, embracing the second degree does not imply embracing the third. But embracing the third does not imply embracing the second either. The third presupposes resources adequate for defining the notion of a converse $-R$ and $R^{\star}$ are converses if they differ solely in the order that they apply to things they relate. But just because a notion is definable, this doesn't commit anyone who admits the third degree to there actually being, as the second degree demands, relations that differ solely in respect of the order in which they apply to things.

\section{Troublesome Consequences of the Second and Third Degrees}

The consequences of the second and third degrees spell trouble. The second commits us to a superfluity of converse relations and states that arise from their application. If we restrict ourselves to binary relations, converses might seem familiar enough because we have names for many of them and the grammatical device of passivisation - "after" as well as "before", "less" as well as "greater", "loves" as well as "is loved by". But we shouldn't think that converse relations are familiar old friends. Each ternary non-symmetric relation has 5 mutual converses, and we don't have names for any of them. Things only get worse when we consider that each quaternary non-symmetric relation has 23 converses, etc.

The number of converse relations to which the second degree commits us is not the only problem. As Russell and Fine emphasise, there's a problem with the profusion of states that arise from the application of these relations too [Russell 1903: §219, Fine 2000: 3-5]. This is evident even in the case of binary relations. It's one kind of undertaking to put the cat on the mat, something else to put the mat under the cat, but however we go about it we end up with the same end state. To bring the cat to the forefront of our 
audience's attention we describe this state by saying that the cat is on the mat; to bring the mat into the conversational foreground we say that the mat is under the cat. But whether it's the cat we mention first, or the mat, what we succeed in describing is the very same cat-mat orientation. That's intuitive but if-as the second degree describes - a non-symmetric relation and its converse are distinct we must be demanding something different from the world, a different state, when we describe the application of the above relation to the cat and the mat from when we describe the application of the below relation to the mat and the cat.

We might attempt to defend the second degree by maintaining that the application of $R$ and $R^{*}$ do not give rise to different states with respect to the same relata but different decompositions of the same state. So whilst above and below are distinct, the relational configuration cat-above-mat is a decomposition of the same state as the configuration mat-below-cat. But these decompositions comprise what are ultimately different constituents-a non-symmetric relation and its converse are supposed to be distinct existences. But now we have the difficulty of explaining how such different decompositions can give rise to a single state. And admitting such polymorphous states still does nothing to reduce the superfluity of converses.

To embrace the second degree, though, isn't merely to acknowledge relations and states of whose existence we were previously unsuspecting. It's also to be committed to the substantive linguistic doctrine that the grammatical transformation from the active voice ("Antony loves Cleopatra") to the passive ("Cleopatra is loved by Antony") inevitably introduces a novel subject matter, switching our attention from one non-symmetric relation to another. ${ }^{3}$ What's more, embracing the second degree gives rise to a battery of necessary connexions - because necessarily if $a R b$ then $b R^{\star} a$. So the troublesome consequences of embracing the second-degree aren't just to do with the number of relations and states to which we are thereby committed.

${ }^{3}$ Contra, e.g., the treatment of passive sentences presented in Parsons' [1990: 91-2]. 
Whilst Russell and Fine emphasise the ontological difficulties that arise from admitting converses they do not consider the third degree. In fact its consequences are even more troublesome. The third degree commits us to an unwholesome profusion of recherché fine-grained facts of the matter about how relations apply, facts of the matter that provide a basis for non-arbitrary comparisons between the applications of relations of any degree. Consider the states:

Lo Antony is to the left of Fulvia

$H_{0}$ Antony is the husband of Fulvia

The third degree commits us to there being a fact of the matter about whether it is Antony or Fulvia that comes first with respect to $\mathrm{L}_{0}$. It also commits us to there being a fact of the matter about which of them comes first in $H_{0}$. And we will thereby be committed to there being a fact of the matter about whether Antony comes first in both states or first in one or second in both. We will also be committed, in light of the further state,

No Alexandria is north of Memphis

to a fact of the matter about whether with respect to $H_{0}$ and $N_{0}$ it is Antony and Alexandria that have something in common by virtue of both coming first, or Fulvia and Memphis, or Antony and Memphis, or Fulvia and Alexandria. We will even be committed, because of the state,

$B_{0}$ Memphis is between Alexandria and Diospolis

to a fact of the matter about whether with respect to $H_{0}$ and $B_{0}$ it is Alexandria and Diospolis that have something in common with Antony and Fulvia by virtue of coming first and second respectively or Alexandria and Diospolis and Fulvia and Antony, or Diospolis and Alexandria and Antony and Fulvia, or Diospolis and Alexandria and Fulvia and Antony, or Memphis and Alexandria 
and Antony and Fulvia, or Memphis and Alexandria and Fulvia and Antony, or Alexandria and Memphis and Antony and Fulvia, or Alexandria and Memphis and Fulvia and Antony, or Memphis and Diaspolis and Antony and Fulvia, or Diaspolis and Memphis and Fulvia and Antony.

It isn't a case of hyperbolic scepticism to be doubtful that such facts of the matter are out there; or, to put the point metaphorically, doubtful that we can make sense of asking all the non-symmetric relations to line up and put their first foot forward. The relating relation of $L_{0}$ appears to do no more than arrange one relatum to the left of the other. There is nothing in the description of $L_{0}$, or the manner in which the scene presents itself, to indicate that its relation imposes an inherent order upon the things it relates. So we can have no non-arbitrary basis for supposing that being to the left of applies to Antony first and Fulvia second rather than the other way around. Similarly there is nothing in the description of $\mathrm{H}_{0}$ to settle that it is Antony rather than Fulvia that comes first in their relationship-if we are talking about a gender egalitarian society. Nor is there anything in the description of $N_{0}$ to indicate that it is Alexandria rather than Memphis that comes first, or in the description of $B_{0}$ that indicates it is Memphis rather than Alexandria or Diospolis that comes first. So there can be no non-arbitrary basis either for making inter-state comparisons between the different ways that their relating relations give rise to the states $L_{0}, H_{0}, N_{0}$ and $B_{0}$.

What's problematic about the third degree isn't what's problematic about the second. The second degree begets what appears to be an egregious supply of converse relations and their states. If the benefits of a theory that posited converse relations outweighed its costs we'd have reason enough to acknowledge all of these things. But even if we have reason to embrace such an abundant ontology this won't mitigate the problematic consequences of embracing the third degree. What's problematic with the third degree isn't to do with there being too many facts of the matter ( $a R b$ and $\left.b R^{\star} a\right)$. It's to do with there being only one fact of the matter about which thing a given relation applies to first, which second etc., with respect to a given 
state, and there being no means of settling which of many different possible facts of the matter is the one truly realised.

This strong consequence of the third degree may be expressed using lambda notation. Relatedness in the third degree does not regard relational states - as the first degree leaves open - as mere points in logical space. It conceives of them as essentially endowed with a constructional history. According to the third degree, there are two different histories whereby the state $a R b$ may have emerged into the world. It may have been the result of $R$ 's applying to $a$ first and $b$ second. Or it may have been the result of $R$ 's applying to $b$ first and $a$ second. We can represent the difference between these possible histories by saying that $a R b$ is either the value of the function $\lambda x \lambda y x R y$ for the arguments $a$ and $b$ (in that order) or it's the value of the function $\lambda x \lambda y y R x$ for the arguments $b$ and $a$ (in that order). ${ }^{4}$ But " $\lambda x \lambda y x R y$ $(a)(b)$ " and " $\lambda x \lambda y y R x(b)(a)$ " don't appear to describe different possible ways in which the state $a R b$ may have arisen. These statements appear no more than notational variants of one another-albeit that they exploit our twodimensional script in different ways to encode the same information about how $a$ and $b$ are $R$-related. ${ }^{5}$ But embracing the third degree implies that only one of these statements is true and that there is a fact of the matter concerning which one-even though there is nothing about our descriptions of the world that provides a non-arbitrary basis for determining the matter.

The problem with acknowledging that there's a fact of the matter about which thing, with respect to a given state, $R$ applies to first, which second, isn't just that we can't know what it is. It's that the fact in question is a very strange beast indeed. It's one that's disconnected from all other kinds of facts of the matter to which we are committed by our common sense and scientific worldviews. Consider once more $L_{0}$ : Antony is to the left of Fulvia. If we

\footnotetext{
${ }^{4}$ Deploying Church's lambda notation to represent converse functions [1941: 7].

${ }^{5}$ Here, a language like English which exploits word-order to encode information about how $a$ and $b$ are related may give rise to an appearance of (third degree) order where, e.g., Latin or Sanskrit avoids doing so because this information is carried using inflected nouns that can appear in any order.
} 
embrace the third degree then either $L_{0}$ is generated by being to the left of applying to Antony first, Fulvia second, or Lo comes about the other way around. Suppose that the former is really the case. This fact can't be logically squeezed out of our description of $L_{0}$ nor does anything else follow from it except that it isn't the case that Fulvia comes first, Antony second. This makes positing such facts of the matter quite unlike (e.g.) positing molecules to explain the phenomenon of heat. Molecules have the welcome feature of enabling us to connect together otherwise disparate phenomena, to achieve a level of theoretical unification that would otherwise be unobtainable, arguably a key desideratum of a scientific theory [Kitcher 1989]. By contrast embracing relatedness in the third degree commits us to a plethora of facts of matters that connect with, and therefore explain, nothing else.

\section{Contrast the Near Indubitable Status of First-Degree Relatedness}

The unwholesome consequences of the second and third degrees provide us with a reason for renouncing them. Matters stand quite differently with the first degree whose acceptance is mandatory if we think there are non-symmetric relations. That there are two different ways for loves to apply to Antony and Cleopatra-that Antony's loving Cleopatra is different from Cleopatra's loving Antony - would be extraordinary to deny. Indeed the very logic of relations forces the first degree upon us. If $a R b$ weren't different from $b R a$ then $a R b$ would be the case whenever bRa was. But this would just be to affirm that $R$ was symmetric rather than non-symmetric. So if there are non-symmetric relations at all, we will need to acknowledge that there are different ways in which they may apply to the things they relate. We will need to embrace the first degree if we are to make sense of the world as a totality of (nonsymmetrically) related things.

Consider the debate about whether time might be circular; whether $A$ might be before $B$ even though $B$ is before $A$. For this to be a significant issue we need to be able to distinguish $A$ 's being before $B$ from $B$ 's being before $A$. If we think that time might be circular then we think that there is a possible cosmological setup in which these two states co-habit together. But if we think 
that time cannot be circular then we think that such setups are impossible. But to make sense of the debate about whether time might be circular we haven't needed to resort to distinguishing before from after-i.e. haven't needed to distinguish between converses. It's true that we can describe circular time as the possibility that $A$ and $B$ are both before and after one another. But there's no need; we can simply describe circular time as the possibility that $A$ is before $B$ and $B$ is before $A$. Nor have we needed to distinguish the state that consists in $A$ 's being before $B$ from the state of $B$ 's being after $A$. And there's no need to distinguish either between before applying to $A$ first and $B$ second and its applying to $B$ first and $A$ second. There's only need to distinguish $A$ 's being before $B$ from $B$ 's being before $A$ [Newton Smith 1980: 202]. So whilst it's necessary to embrace the first degree to make sense of these different cosmological hypotheses it isn't necessary to embrace the second or the third.

What vexes the understanding is the difficulty of disentangling one degree of relatedness from another when we try to provide an analysis of the fundamental fact that $a R b \neq b R a$ for non-symmetric $R$. We can usefully distinguish, albeit in a rough and ready sense, between two analytic strategies for explaining this fundamental fact — that the world exhibits relatedness in the first degree. Intrinsic analyses aim to account for the fact that $a R b \neq b R a$ by appealing to features of those states themselves; extrinsic analyses attempt to account for their difference by appealing to features that aren't wholly local to them. Anyone who wishes to give an analysis of the fact that $a R b \neq b R a$ faces a dilemma. If they adopt the intrinsic strategy then they will find it difficult to avoid a commitment to either $R$ 's converse or an inherent order in which $R$ applies to the things it relates. Alternatively our would-be analyst can avoid entangling the first degree with the second and third by adopting the extrinsic strategy. But this approach embroils us in other unwelcome consequences. Since neither intrinsic nor extrinsic analyses are satisfactory this recommends our taking the fact that $a R b \neq b R a$ to be primitive.

\section{Intrinsic Analyses of First Degree Relatedness}


One natural way to provide an intrinsic analysis of relatedness to the first degree is to appeal to the different order in which $R$ applies to $a$ and $b$ to constitute these states. Such an analysis explains the difference between $a R b$ and $b R a$ as arising from the difference between $R$ applying to $a$ first and $b$ second, and $R$ applying to $b$ first and a second [Grossmann 1983: 164, Hochberg 2001: 215]. This view of relations is implicitly maintained by many and propounded by Grossmann and Hochberg but their analysis leads us straight from the first degree to the third. For any arbitrary relations $R$ and $U$ there must be a fact of the matter about which things they relate first, which second, etc.

Another natural way to account for the difference between $a R b$ and $b R a$ is to appeal to the different "directions" in which $R$ applies to the $a$ and $b$ to constitute these states. This was Russell's aforementioned analysis in The Principles of Mathematics where he sought to account for the difference between $a R b$ and $b R a$ by attributing to $R$ a direction: "it is a characteristic of a relation of two terms that it proceeds, so to speak, from one to the other" [1903: §94]. Russell explained the difference between $a R b$ and $b R a$ as arising from the difference between $R$ proceeding from $a$ to $b$ and $R$ proceeding from $b$ to $a$.

This way of explaining the application of a non-symmetric relationappealing to its direction-also provides for the definition of $R$ 's converse as the relation $R^{*}$ that proceeds from $x$ to $y$ whenever $R$ proceeds from $y$ to $x$. According to Fine, explaining how $a R b$ differs from $b R a$ by appealing to the direction that $R$ applies leads us inexorably from an acknowledgement of the different ways that $R$ may apply to the recognition of the existence of its converse $R^{\star}$. This is because "it would be completely arbitrary to insist that a given relation might exist and yet not a converse" [Fine 2000: 2-3]. It would be completely arbitrary to insist that $R$ truly exists proceeding from $a$ to $b$, whilst banishing its converse, the relation that would have proceeded from $b$ to $a$ if it had existed, to the nether realm. The same point also appears to apply to Grossman and Hochberg's analysis. For it would be no less arbitrary to insist that $R$ truly exists applying to $x$ first and $y$ second, whilst denying the 
existence of its converse, the relation that would have applied to $y$ first and $x$ second if it had existed. We are thereby led, if Fine is right, from the first degree we want to the second degree we don't.

But Fine's line of argument isn't irresistible-not if relations are universals. Assuming universals are sparse it doesn't follow from the fact that the notion of the converse of a relation is definable that there is a corresponding converse relation. No more does it follow that because the notion of grue is definable that there is such a property. So it doesn't follow either that because the difference between $a R b$ and $b R a$ is explained by appealing to the direction or order of $R$ that there is another relation $R^{\star}$ that proceeds in reverse. Of course, $R$ can be defined in terms of $R^{\star}$ too, so the question arises: which relation is it then $-R$ or $R^{\star}$-that really exists? There's no descriptive constraint that favours selecting $R$ rather than $R^{\star}$. If we concentrate solely upon what we do in language or thought then there can be no non-arbitrary answer to this question. But, as Lewis reflected, "it takes two to make a reference, and we will not find the constraint if we look for it always on the wrong side of the relationship" [Lewis 1983: 371]. It may be how reality is itself jointed that favours selecting " $R$ " rather " $R$ " as the expression that corresponds to a genuine universal. In other words, there may be a natural rather than a logical foundation for admitting a non-symmetric relation but not its converse.

Of course this line of thought isn't incontrovertible. It may be only $R$ (or $\left.R^{*}\right)$ that reality actually selects. But since they are distinct-they proceed in opposite directions - the possibility that only $R$ occurs must be distinguished from the possibility that only $R^{\star}$ does. Supposing that "before" and "after" are names of distinct converses, we will thereby be committed to distinguishing the possibility that the Big Bang is before the Big Crunch from the possibility that the Big Crunch is after the Big Bang. But surely there is only one possibility for the cosmos here, not many. Whilst we have avoided multiplying entities in the actual world we have done so only at the cost of unduly multiplying possibilities. 
But even if the slide from the first degree to the second can be resisted-by appeal to the idea of a natural foundation or otherwise-it's still the case that employing the notion of direction to explain the first degree, no less than employing the notion of order, leads us directly to the third. This is because introducing the notion of direction enables us to draw significant comparisons between the applications of different relations to the same terms. Suppose the difference between $a R b$ and $b R a$ is indeed explained by the direction in which $R$ proceeds from one thing to another. Then with regard to $a$ and $b$ there must be a fact of the matter (1) about which of these things, if it relates them, $R$ proceeds from and which to. There must also be a fact of the matter about which of these things another relation $S$, if it relates them, proceeds from and which to. But this means that there must be a further fact of the matter (2) about whether $R$ and $S$ both proceed from $a$, or $R$ proceeds from $a$ and $S$ from $b$, or $R$ from $b$ and $S$ from $a$. More generally, with regard to arbitrary relations $U$ and $V$, there must be a fact of the matter (3) about which things they relate have something in common by virtue of being a thing from which $U$ or $V$ proceed, which things have something in common by virtue of being a thing to which $U$ or $V$ proceed. But these are just the unwanted finegrained facts of the matter generated by the third degree-albeit under an alias.

Williamson has suggested a different kind of intrinsic explanation of the fact that $a R b \neq b R a$ that appeals to the idea that $R$ comes equipped with two argument positions, \% and \#. According to this account, often called 'positionalism', R's application to $a$ and $b$ arises from the assignment of $a$ and $b$ to $R$ 's argument positions. The difference between $a R b$ and $b R a$ is thus explained in terms of the different assignments of $a$ to $\%$ and $b$ to \# in the one case and $b$ to $\%$ and $a$ to \# in the other. ${ }^{6}$ Because relations neither apply first or second to the things they relate, nor proceed from and to them, nor share their argument positions, there is no basis for significant comparisons

\footnotetext{
${ }^{6}$ See Williamson's remark that a binary relation "R has two argument positions" and that we may "speak of putting the entities which $R$ is said to relate themselves into these argument positions" [1985: 257].
} 
between the states to which relations give rise. Without these resources it is not possible to even describe the profusion of facts of the matter that arise from the second and third degrees.

But, as Fine points out, this explanation commits us to an unwelcome proliferation of states involving symmetric relations [Fine 2000: 17-8. MacBride 2007: 36-44]. Take the adjacency relation. According to Williamson, this relation has two argument positions. Call them Next and Nigh. Now suppose that the cat is adjacent to the mouse. Since there are two different ways of assigning the cat and the mouse to Next and Nigh there would appear to be two different states that may arise from the application of adjacency to the things it relates - the state that arises from the assignment of the cat to Next and the mouse to Nigh and the state that arises from the assignment of the mouse to Next and the cat to Nigh. But intuitively there is only one way for a binary symmetric relation like adjacency to apply to the things it relates, only one possible state that can arise from the application of this relation to the things given: either the cat is adjacent to the mat, or not. So whilst an analysis of the difference between $a R b$ and $b R a$ that appeals to the relative assignment of $a$ and $b$ to the argument positions of $R$ succeeds in avoiding the excesses of the second and third degrees it does so only at the cost of over-generating applications for symmetric relations.

A related explanation of the first degree promises to avoid both second and third degree consequences whilst avoiding the proliferation of symmetric states. According to Orillia [2011], the constituents of states that arise from the application of non-symmetric relations have different roles, conceived as the ontological correlates of the thematic roles identified by contemporary semantics [Parsons 1990: 68-104]. The state of Antony's loving Cleopatra has Antony playing the agent role whilst Cleopatra plays the patient role; whereas the state of Cleopatra's loving Antony has Cleopatra playing agent, Antony patient. The difference between these states is explained by role reversal. But there is nothing in this explanation that commits us to the existence of converses. In fact it supplies a ready account of why "Antony loves Cleopatra" and "Cleopatra is loved by Antony" say the same thing: both statements 
describe Antony as agent and Cleopatra as patient with respect to the loves relation. Nor is there anything about this explanation that commits us to third degree consequences since it is not inherent in (e.g.) the notion of an agent that an agent comes first.

So far the 'onto-thematic role' account sounds like positionalism. Indeed we might wonder whether one is merely a re-labelling of the other. Is there really any difference, we might ask, between roles and argument positions? But according to Orillia they're very different. Argument positions are particular in the sense that they cannot be shared by distinct relations nor recur within one. But roles are universals, in the sense that they are capable of recurring not only within a single state but also across states that arise from the application of distinct relations. By holding that roles are capable of being repeated Orillia avoids the proliferation of symmetric states that arise from the different possible assignments of the cat and the mat to the two (particular) positions Next and Nigh-because there is only one (universal) role that is performed by both the cat and the mat in the state of the cat being next to the mat there aren't many possible assignments of the cat and the mat to it. Holding that roles are capable of being repeated also enables Orillia to maintain that there are genuine inter-state comparisons to be drawn, comparisons that have "nothing to do with the relating relation... or with the arguments" but arise from the fact that the same ontological roles are realised in many varied states [2011: 5].

Yet whilst the onto-thematic approach avoids the second and third degrees it generates consequences that are almost as strong. This is because with respect to any state that arises from the application of a nonsymmetric relation this approach is committed to there being distinct roles that each of the relata performs. But there are many such states whose nonrelational constituents don't appear to perform different ontological roles - just as there are many states whose constituents don't appear to be inherently first or second. Recall Lo: Antony is to the left of Fulvia. It doesn't appear that Antony is the agent whilst Fulvia is the patient of this state-anymore than it appears that Antony comes first and Fulvia second. And there's nothing else 
that can be logically squeezed out of the description of $L_{0}$ to determine that Antony performs an ontological role that Fulvia doesn't, over and above Antony's being to the left of Fulvia - which is simply to repeat what's already been said. It's similarly unclear that 5 performs a role distinct from 7's in the state $5>7$, over and above 5 's being greater than 7 .

Of course, if the onto-thematic roles things perform have "nothing to do", as Orillia claims (ibid.), with the character of the relations that apply to them, then we shouldn't expect to be able to distinguish (e.g.) agent from patient by dwelling upon descriptions of how Antony and Fulvia, or 5 and 7 , are related. But suppose descriptions of the roles things perform really are logically detached in this manner from our descriptions of how they are related. Then even though there may be a fact of the matter about which roles things perform, nothing we ever say about them will provide a reason for supposing that they perform one role rather than another. It won't even be clear what it means to describe something as an agent when this is logically detached from describing it as something that performs actions by entering into certain characteristic relations with other things - by perceiving, moving, eating, etc.

There is another problem for positionalism and the onto-thematic approach, something more of an 'Emperor's New Clothes' objection. These views explain the first degree by making indispensable appeal to the results of applying a non-symmetric relation (assignment) whose domain includes $R$ 's relata $(a$ and $b)$ and whose range includes $R$ 's argument positions or roles (\% and \#). The difference between $a R b$ and $b R a$ arises inter alia from the difference between assignment holding between $a$ and \% on the one hand, and holding between $a$ and \# on the other. This reveals the need for an account of how assignment itself applies to the things it relates. But if this account appeals in turn to argument positions or roles associated with assignment ( $£$ and $\$$ ) then vicious regress beckons - we will need to explain the application of whatever relation relates assignment to them. And if we attempt to forestall the regress by denying that any account is needed of how assignment applies to its relata it becomes questionable whether an account 
was ever needed of how $R$ applies. These and other difficulties that beset intrinsic analyses provide a motive for exploring the possibility of an extrinsic analysis of first-degree relatedness.

\section{Extrinsic Analyses of First-Degree Relatedness}

Relations are generally said to be instantiated or exemplified by sequences of things; sometimes they are described as properties of sequences [Quine 1960: 257, Kim 1993: 8]. Van Inwagen maintains that if we take this way of talking about relations as properties seriously then we can explain the difference between $a R b$ and $b R a$ as arising from the difference between $R$ being instantiated by one sequence of $a$ and $b$ and $R$ being instantiated by another [2006: 468]. According to this account, the application of a relation to the things it relates is not direct but mediated via the existence of something else, namely a sequence of them. Since a sequence is something over and above the things arranged by it, such an analysis counts, for present purposes, as extrinsic.

Analyses that appeal to sequences provide for the institution of the notion of a converse: $R^{\star}$ is a converse of $R$ if whenever $R$ is instantiated by a sequence $k, R^{*}$ is instantiated by a permutation of $k, p(k)$-for $k$ to instantiate one of these relations is for $p(k)$ to instantiate the other. But unless we have already adopted an abundant theory of properties and relations it doesn't follow that if $R$ exists then $R^{*}$ exists too. So these analyses do not immediately generate second degree consequences.

But such analyses do generate third degree consequences. Suppose that a relation $U$ applies to some things $a, b, c \ldots$ by virtue of being instantiated by a sequence of them. A sequence arranges its constituents in an order. So there must be a fact of the matter about which of them comes first, second, third... in the sequence. Since it is the order in which the sequence arranges its constituents that provides the basis for $U$ applying one way rather than another, there must be a fact of the matter about which of these things $U$ relates firstly, secondly, thirdly... Similarly with regard to any relation $V$ that applies to $\alpha, \beta, \gamma \ldots$ there must be a fact of the matter about which of them $V$ 
relates firstly, secondly, thirdly.... But this means that there must be an interstate fact of the matter about whether it is $a$ and $\alpha$ or $a$ and $\beta \ldots$ that $U$ and $V$ relate firstly or secondly or thirdly.... If we wish to avoid the consequences of the third degree we will have to look elsewhere.

Fine offers a radically different extrinsic analysis of the first degree.

Fine fashions his analysis to avoid generating second degree consequences but it also avoids third degree consequences. What makes it the case that $a R b$ rather than $b R a$ is just the fact that the state that results from the application of $R$ to $a$ and $b$, say $a R b$, arises "in the same manner" as another state, $c R d$, that also results from the application of $R$. The difference between $a R b$ and $b R a$ is explained by the "external" connections between these states. What makes the difference between Antony's loving Cleopatra $\left(s_{0}\right)$ and Cleopatra's loving Antony ( $s_{o}{ }^{\prime}$ ) isn't determined by peering inside these states. Instead we must lift our gaze outward to other states to which loves gives rise. Take Abelard's loving Eloise $\left(t_{0}\right)$ to be an exemplar of another such state: "Then we may distinguish between $\left(s_{0}\right)$ and $\left(s_{o}\right.$ ) on the grounds that $\left(s_{0}\right)$ is the completion by Antony and Cleopatra in the same manner in which $\left(t_{o}\right)$ is the completion by Abelard and Eloise, while ( $\left.s_{o}^{\prime}\right)$ is not. Thus the different states will be distinguished, not by how they derive from the given relation and its relata, but by how they are interconnected" [Fine 2000:21]..$^{8}$ The interconnections in question are relationships of substitution between $\left(s_{0}\right)$ and $\left(t_{o}\right)$ to which Fine appeals to make sense of the fact that loves applies to Antony and Cleopatra in the same manner that it applies to Abelard and Eloise so as to give rise to $\left(s_{o}\right)$ and $\left(t_{0}\right)$ respectively.

Fine's account of the first degree avoids the second and third because it eschews the notions of direction and order that are required to articulate a commitment to converses and recherché facts of the matter about how relations apply. But this is only because his account passes beyond the first degree to embrace another of intermediate strength-degree 1.5. Fine's

\footnotetext{
${ }^{7}$ A similar difficulty afflicts Bergmann [1981: 146-7] and Chisholm [1996: 513] who seek to mimic the Wiener-Kuratowski account of sequences as classes of classes.
}

${ }^{8}$ See MacBride [2007: 47-53] for further criticism of Fine's analysis 
account of how $a R b$ and $b R a$ are distinguished refrains from presupposing that there are intelligible comparisons between states arising from the application of $R$ and others arising from the application of relations other than $R$-whether $R$ 's converse or some other relation $U$. But it does presuppose that there are other states, say $c R d$, that arise from the application of $R$ to other things. Fine uses the interconnections between these $R$-states to distinguish $a R b$ from $b R a$. So this account doesn't merely embrace the first degree because it doesn't merely distinguish between the ways that $R$ potentially applies to some given things. It also presupposes that there are other interconnected states that arise from $R$ 's application to other things.

The strength of Fine's account that enables it to avoid the second and third degrees also makes it vulnerable. It is a feature of our ordinary thinking about relations that, for a significant class of them, their application is compatible with loneliness: it is possible for $R$ to apply to $a$ and $b$ even though there are no other things to which $R$ applies. For example, we think it is possible for Antony to have loved Cleopatra even in circumstances where no one else loved anyone-possible circumstances in which even Abelard didn't love Eloise. Embracing the first degree leaves open the possibility of lonely applications of relations because it is silent about whether $R$ applies to anything other than $a$ and $b$. But embracing relatedness to degree 1.5 precludes this possibility because it requires the existence of other things to which $R$ applies. Because of this commitment, Fine's account is incompatible with loneliness.

\section{Conclusion: An Account that's not an Analysis}

The fact that any attempt to provide an analysis of relatedness in the first degree has invariably come unstuck ought to make us take seriously the idea that we were mistaken from the start to seek an analysis of the application of relations. Because neither intrinsic nor extrinsic analyses have proved satisfactory we should just take the difference between $a R b$ and $b R a$ as primitive. This means that our understanding of what makes the difference between $a R b$ and $b R a$ in general is schematic - it depends in particular cases 
upon the character of the $R$ in question. Sometimes it may be helpful to appeal to the notion of an agent or patient to elucidate the distinction between (e.g.) loves applying one way rather than another. But there are many relational states where roles like agent and patient don't get a grip, (e.g.) temporal and mathematical states.

We have become familiar with the idea that it is appropriate to take a concept, such as knowledge, as primitive-in part because attempts to analyse it in terms of other concepts, such as belief, truth and justification, have proved fruitless [Williamson 2002: 30-1]. It is even more compelling to suppose that some forms of combination, such as predication or functional application, are primitive too. To admit relatedness in the first degree is to admit a certain kind of relational operation - the operation that consists in the application of $R$ to $a$ and $b$ to yield the values $a R b$ and $b R a$. The difficulties that result from attempting to analyse the first degree suggest that that the operation of relational application should itself be taken as primitive. ${ }^{9}$

Does refraining from providing an analysis mean shirking an obligatory task for systematic philosophy? No. Remember what Lewis said: "Not every account is an analysis!" [1983: 352]. A system that takes the fact that $a R b$ is different from $b R a$ as primitive cannot be accused of failing to make a place for it. There remains a question about theory choice we cannot shirk: whether a system that takes the first degree as primitive is to be preferred to a system

\footnotetext{
${ }^{9}$ Referring to an earlier draft of the present paper, Gaskin \& Hill [2012: 184] also recommend taking order as primitive but their reasons for doing so differ from those presented here. They reject Russell's "directionalism" because of the problem of converses but they do not distinguish the second from the third degree, fail to recognize that Russell may avoid converses anyway, nor acknowledge directionalism's independent third degree consequences. Following Fine, they reject positionalism because of its commitment to argument positions and the problems it encounters with the identity of symmetric states; but they fail to note the vicious regress that also threatens positionalism. They reject Fine's "anti-positionalism" because the substitution relation "cannot create" but merely preserves structure. This last objection may beg the question against Fine because it's not obvious that antipositionalism aims to reduce facts about structure to facts about substitution. But for present purposes nothing hangs upon this. My objection to Fine, that anti-positionalism violates the possibility of lonely applications of nonsymmetric relations, applies even if their objection to Fine fails.
} 
that analyses it. Since systems that purport to provide an analysis have embroiled us in unwholesome second and third degree consequences we have reason to favour systems that take the first degree as primitive. Taking the plethora of different ways that a non-symmetric relation $R$ is capable of applying to its terms as primitive-what can be expressed by saying that the difference between $a R b$ and $b R a$ is ultimate and irreducible-appears as judicious a choice of theory as any to make, an entirely respectable form of 'ostrich realism': 'realist' because it acknowledges relations, 'ostrich' because it takes the manner of their application to be primitive. ${ }^{10}$

University of Glasgow

\section{REFERENCES}

Armstrong, D.M. 1978. Nominalism \& Realism. Cambridge: CUP.

Bergmann, G. 1981. Notes on Ontology, Noûs 15/2:131-54.

Butterfield, J. 2006. Against Pointillisme About Mechanics, British Journal for the Philosophy of Science 57/4: 709-754.

Butterfield, J. 2011. Against Pointillisme: A Call to Arms, Explanation, Prediction and Confirmation, ed. D. Dieks, Dordrecht: Springer: 347-366.

Chisholm, R.M.1996. A Realistic Theory of Categories. Cambridge: CUP. Church, A. 1941. The Calculi of Lambda-Conversion. Princeton: Princeton University Press.

Fine, K. 2000. Neutral Relations, Philosophical Review 199/1: 1-33.

Gaskin, R. \& Hill, D. 2012. On Neutral Relations, Dialectica 66/1: 167-86.

Grossmann, R. 1983. The Categorical Structure of the World. Bloomington: Indiana University Press.

Hochberg, H. 2001: The Positivist and the Ontologist: Bergmann, Carnap and Logical Realism. Amsterdam: Rodopi B.V.

10 I am especially grateful to Kit Fine and Herbert Hochberg. I would also like to thank audiences at the Universities of East Anglia, Geneva, Liverpool, London and Stirling and Jeremy Butterfield, Ghislain Ghuighon, Jane Heal, Frédérique Janssen-Lauret, Nick Jones, E.J. Lowe, Laurie Paul, Bryan Pickel, Hugh Mellor, Stewart Shapiro and Alan Weir for further discussion. This paper was written during a period of leave supported by the AHRC. 
Kim, J. 1993. Supervenience and Mind. Cambridge: CUP.

Kitcher, P. 1989. Explanatory Unification and the Causal Structure of the

World" in Scientific Explanation, P. Kitcher and W. Salmon, Minneapolis:

University of Minnesota: 410-505.

Lewis, D. 1983. New Work for a Theory of Universals, Australasian Journal of Philosophy 61/4: 343-77.

Lewis, D. 2002. Tensing the Copula, Mind 111/441: 1-12.

MacBride, F. 2007. Neutral Relations Revisited, Dialectica 61/1: 25-56.

Newton-Smith, W.H. 1980. The Structure of Time. London: RKP.

Orillia, F. 2011. Relational Order and Onto-Thematic Roles, Metaphysica 12/1: 1-18.

Parsons, T. 1990. Events in the Semantics of English. Cambridge, MA: MIT Press.

Quine, W.V.O. 1960: Word \& Object. Cambridge MA: MIT Press.

Russell, B. 1903. The Principles of Mathematics. London: George Allen \& Unwin.

Shapiro, S. 1991. Foundations without Foundationalism. Oxford: Clarendon. Van Inwagen, P. 2006. Names for Relations, Philosophical Perspectives 20/1: 453-77.

Williamson, T. 1985. Converse Relations, Philosophical Review 94/2, 249262.

Williamson T. 2002. Knowledge \& Its Limits. Oxford: OUP. 